\title{
LA COMPETENCIA TERMINOLÓGICA: CAUSAS LINGÜÍSTICAS EN EL AUGE DEL TÉRMINO SOSA Y EL DECLIVE DE BARRILLA EN LOS SIGLOS XVIII Y XIX ${ }^{1}$
}

\author{
Lidia Sala Caja \\ Universidad Provincial de Aichi (Japón)
}

\section{RESUMEN}

Desde la Edad Media las cenizas de las plantas solían emplearse en toda Europa en la elaboración del jabón y del vidrio. Estas cenizas eran conocidas con diferentes términos derivados de los vegetales empleados y la cualidad del producto. En España la sosa y la barrilla eran las más extendidas. Debido a la reconceptualización de sus referencias iniciales, ambas denominaciones sufrieron considerables cambios semánticos durante los siglos XVIII y XIX. El propósito de este artículo es observar estos cambios subrayando los factores intralingüísticos.

PALABRAS CLAVE: Edad Media, botánica, sosa, barrilla, siglos XVIII y XIX.

\section{SUMMARY}

From the Middle Ages onwards plant ashes were commonly used throughrout Europe in the elaboration of soap and glass. These ashes were known by different names depending on the vegetables employed and the quality of the product. In Spain sosa (soda) and barrilla (barilla) were the most widespread.

Due to the reconceptualization of their primary references, these two words underwent considerable semantic changes during the XVIIIth and the XIXth centuries. The aim of this paper is to survey these changes focusing on their intralinguistic factors.

KEY WORDS: Middle Ages, botany, soda, barilla, XVIII ${ }^{\text {th }}$ and XIX ${ }^{\text {th }}$ centuries.

1 Este trabajo forma parte del proyecto de investigación Catálogo de neologismos del léxico científico y técnico del s.XIX, financiado parcialmente por el MCYT (BFF 2001-2478). 


\section{INTRODUCCIÓN}

A pesar de que tanto la ciencia positivista como la primera terminología insistieran en propugnar definiciones muy rígidas de término (monosémico, biunívoco), desde siempre se ha sabido que no podían ser otra cosa que idealizaciones, pues la realidad las desmentía con incesantes ejemplos de polisemia, sinonimia, tránsito léxico entre disciplinas, etc. ${ }^{2}$

Fenómenos léxico-semánticos como los anteriores intervinieron en la evolución histórica de los términos sosa y potasa. Nacidos en otros campos, en el siglo XVIII se inocularon a la nomenclatura química sin perder los significados anteriores a su empleo como términos, de modo que generaron a su alrededor una polisemia y una sinonimia asombrosa si tenemos en cuenta que ambos pertenecían a una disciplina que se jactaba de tener un lenguaje sistemático ${ }^{3}$.

En estos «alrededores» se encontraba también barrilla, una voz de origen peninsular. Durante los siglos XVII y XVIII la magnitud e importancia comercial $^{4}$ del producto que nombraba había reforzado y extendido su empleo

2 Las nuevas definiciones del lenguaje científico han reinterpretado su significación al incorporar su naturaleza textual y pragmática. También el abandono de la imagen naif que la idea de traducción arrastraba para los textos de especialidad ha ayudado a matizarlos. En estos nuevos planteamientos está bien presente la simbiosis entre los estudios de lengua y ciencia alcanzada en los últimos años. Para estos nuevos enfoques dentro del panorama español pueden consultarse, entre otros, a GuTIÉRrez Rodilla, B. (1998), La ciencia empieza en la palabra, Barcelona, Península; García Belmar, A. y Bertomeu SÁnchez, J. R. (1999), Nombrar la materia. Una introducción histórica a la terminología química, Barcelona, Ediciones del Serbal. Desde el campo de las humanidades, los Coloquios sobre la Historia de los Lenguajes Iberorrománicos de especialidad, celebrados en la Universidad Pompeu Fabra los años 1997, 1999 y 2001, ofrecen una buena panorámica sobre este tema. Por último, para una reflexión sobre la idea de traducción científica es muy recomendable el artículo de SAKURAI, S. (2001), «Translation and Science», Meta, XLVI, 4, p. 646-663.

3 La polisemia resulta asombrosa no tanto por la cantidad de significados como por la confluencia de estos en los mismos contextos.

4 Aunque la barrilla ya era un producto comercial importante antes, desde las últimas décadas del XVII el aumento de la demanda por otras economías europeas expande e intensifica su cultivo. Durante la Ilustración su explotación formó parte de la retórica sobre el malogro de lo recursos naturales del país por falta de infraestructuras. Véase por ejemplo UlLOA, B.D. (1740), Restablecimiento De Las Fábricas Y Comercio Español, Madrid, Instituto De Cooperación Iberoamericana. Sociedad Estatal Quinto Centenario. Antoni Bosch, Instituto De Estudios Fiscales. Sobre la comercialización de la sosa y la barrilla en Inglaterra puede consultarse ClOw, A. y CLOW, N. L. (1992), The chemical revolution, Philadelphia, Gordon and 
llegando a equipararse con sosa. El declive de la demanda tras la puesta en marcha de los procedimientos de Leblanc y Solvay, que sustituían los productos que ambas denominaban, las afectó de manera desigual. A finales del siglo XIX el uso de barrilla había menguado fundamentalmente a una sola acepción, la botánica, mientras que sosa, por el contrario, había sido agraciada con nuevos significados.

Mi intención en este artículo es examinar la trayectoria de ambos términos e intentar desentrañar los aspectos más lingüísticos que contribuyeron a tal desenlace. No obstante, sus peripecias evocarán entre otras cosas las interacciones entre disciplinas o, en la medida en que es descrita su situación en la lengua española, cómo el conocimiento científico se acomoda en los contextos locales caracterizándolos. Espero que pueda ser de provecho para los interesados en la historia de la lengua y de la ciencia.

\section{El MUNDO DE LAS ARTES: LAS CENIZAS DE LAS PLANTAS}

Ya en la Edad Media se utilizaban las cenizas de varias plantas para fabricar jabón y vidrio así como para cauterizar las heridas. Eran un producto comercial de primer orden para cuyo transporte se reducían lo máximo posible en masas compactas, y así se vendían. Con anterioridad se habían utilizado con este fin los yacimientos de sosa del Bajo Egipto. A este producto se le conocía como natrón. A las cenizas, en cambio, era impensable nombrarlas bajo un mismo nombre, a pesar del similar proceso de elaboración, puesto que su calidad variaba enormemente según su procedencia. Unas se extraían de las cenizas de los árboles leñosos; otras de plantas que crecían en los saladares o cerca del mar.

Los nombres que recibían en las distintas lenguas o países podían recordar la materia prima de donde se extraían como en tartre (tártaro, rasuras de vino), salicor ${ }^{5}$, weedash (cenizas de maleza) o varech ${ }^{6}$; el color, como en pear-

Breach Science Publication. Para España, FERnÁndez PÉREZ, J. (1998), «La elaboración de la sosa en España: de la barrilla a la fábrica de Solvay de Torrelavega», Antilia, 4, art. $1^{\circ}$. (www.uned.es/ca-jaen-ubeda/comunicaciones/pólvora ).

5 La voz, procedente del catalán, nombraba también las cenizas de varias plantas. El Diccionari català valencià balear distingue entre un salicor fino (Salsola soda) y otro grueso (Salicornia fructicosa) en Valencia. En los alrededores de Narbona nombraba principalmente a la Salicornia geniculata. Alcover, A. M. y Moll, F. de B. (1975), Diccionari català valencià balear, Palma de Mallorca, Moll. De ahora en adelante DCVB. 
lash (cenizas perladas) y blanqueta ${ }^{7}$; o por metonimia el de los recipientes donde se producía, como en pottaschen (cenizas de pucheros). En España los más corrientes eran sosa y barrilla ${ }^{8}$.

\subsection{Sosa y barrilla}

Sosa procede de la voz arábica sauda, originalmente adjetivo con el sentido de 'negra' por el color de una de las plantas, que el castellano tomó a través del catalán'. En castellano el Corpus diacrónico del Español (CORDE) proporciona ocurrencias desde $1300^{10}$. Estas documentaciones más tempranas aluden a transacciones económicas y en ellas sosa se refiere al producto elaborado. El mismo étimo se halla en la base del italiano soda, que pasó al francés con posterioridad.

A juicio de Joan Corominas, en el Principado sosa se refería en exclusiva a la Salsola soda, pero como producto elaborado podía nombrar a las cenizas de esta y otras plantas ${ }^{11}$. La popularización tanto de la técnica como de su mercadeo habría provocado que especies explotadas con el mismo fin adoptaran también sosa con algún tipo de especificación para poderlas distinguir correctamente $^{12} \mathrm{o}$ en alternancia con nombres autóctonos. Pero a la hora de vender todas intentarían ser sosa a secas, dado su valor de venta.

Por otro lado, la etimología de barrilla fue discutida largo tiempo en varias ocasiones hasta que el mismo Corominas la esclareció. Procede de barrella, voz mozárabe del País Valenciano y las Tierras del Ebro para la Salsola mandía.

6 El varech es un tipo de alga Fucus. Los centros de producción se localizaban en Nor-

7 La blanqueta se obtenía de la Salicornia altiplex y se llamaba también de Aiguesmortes, la ciudad de Llenguadoc donde se producía.

8 Había otras variedades con otros nombres, como por ejemplo aguazul o almarjo. El italianismo soda figura en los textos desde el siglo XVII pero es poco habitual.

9 Corominas, J. y PAScual, J.A. (1980-91), Diccionario crítico etimológico castellano e hispánico. Madrid: Gredos, 6 v. De ahora en adelante DCECH.

10 La primera documentación de sosa se encuentra en un documento notarial: «De arrova de greda o de sosa, I. meaia» Anónimo, Fuero de Alarcón.

11 Coromines, J. (1980), Diccionari Etimològic i complementari de la llengua catalana, Barcelona, Curial. De ahora en adelante DECLC.

12 El DCVB enumera las siguientes: sosa blanca (Salsola vermiculata), sosa negra o sosa prima (Suaeda altisima), sosa dura, sosa grossa (Salicornia fructicosa) y sosa sabonera (Anthrocneum glaucum). 
kali, que se documenta como nombre de lugar desde el siglo XIII. Esta voz habría partido de parrella, seguramente diminutivo de parra, que es como los pobladores desplazados hasta el reino de Valencia habrían llamado primero a la planta por su similitud con una parrilla.

Al entrar en contacto con la población mozárabe habría evolucionado a barrella $^{13}$. Después se extendería al Reino de Murcia y se castellanizaría como barrilla, no antes del siglo XIV, tras lo cual amplió su área de uso a Almería y Granada. En todo caso el proceso de incorporación al castellano se habría completado en el siglo XVI, momento en que el CORDE dispone de su primera atestación ${ }^{14}$.

Si bien en el Principado parrella aludía tan sólo a la Salsola kali, en zonas levantinas amplió su referencia a otras especies de Salsola, como la $S$. soda. Otra, cultivada en Alicante, sobresalía por la calidad de sus cenizas, motivo por lo cual se la distinguía como barrella fina. El adjetivo ya trasluce que se trataba de un producto para las artes, como en efecto así era: para la fabricación del vidrio se la prefería a cualquier otra. Por lo demás, la antigüedad del adjetivo permite augurar a la lexía cierta solera a pesar de no poder documentarla ${ }^{15}$.

13 «La distribució general de les dues variants dóna la clau de l'etimologia, parrella en el Nord, barrella en el Migjorn, coincidint aquesta amb les terres de l'antic llenguatge mossàrab: és evident, per tant, que parrella ha de ser la variant primitiva y barrella l'arabitzada, amb canvi de $p$ - a $b$-». DECLC.

14 «Y, assí, digo que el primero y mejor vidro es el de Valdepeñas, en la sierra de Jaén, quando es mezclada la varrilla con la arena del Peñón de Susaña, que es en el término de Martos, junto al río de Víboras, que no quando la mezclan con la arena de Cambil. Y la de Cambil haze el vidrio más claro, aunque no es tan denso como quando se mezcla con la del dicho. El segundo, el de María. El tercero es el de Sevilla, quando se labra la barrilla de Levante, porque la que se coxe en la tierra de Sevilla no es buena para esta arte». SANTIAGO, D. $\mathrm{DE}$ (1598), Arte separatoria y modo de apartar todos los licores que se sacan por vía de destilación, p. I, FOL. 4V y 4R. En el CORDE. Hay una documentación anterior con fecha de 1527 en el ejemplo del artículo Almarjo del Diccionario histórico de la lengua español (1933), Madrid, Real Academia: «Otrosi los vecinos de Sevilla ... que ficieren el mazacote, barrilla ó almarjo en las tierras de Sevilla que lo fagen ... que el señor del mazacote é barrilla, é almarjo lo pueda sacar». Orden. de Sevilla, Tít. de islas y marismas ed. 1527, f. 30».

15 El adjetivo fino/a se propagó desde el occitano a las demás lenguas románicas. Primero lo acogió el catalán, donde Corominas lo atesta en documentos tan antiguos como los occitanos ( $1^{\text {a }}$ doc. 1094). En castellano hay testimonios de este adjetivo desde el siglo XIII: seda fina 1240, canela fina 1381, porcelana fina 1754 (CORDE). Los ejemplos subrayan su uso en las artes y el comercio con el significado de 'puro' 'afinado'. No es impensable entonces una lexicalización temprana al lado de barrilla o sosa. 
Puede decirse por tanto que el mismo proceso de generalización-especificación que se producía con la voz sosa/soda en zonas más septentrionales, estaba repitiéndolo barrella/barrilla en el Reino de Valencia y el de Murcia. También la voz salicor (con variantes según se dijera en Valencia, Cataluña o Llenguadoc) pertenecía a ese grupo, y como ellas entró en la misma dinámica, aunque en menor medida ${ }^{16}$. Entre ellas, el criterio de distinción lo daba más la calidad del género producido que la morfología de la planta.

Aunque fenómenos como estos son habituales en el campo semántico del reino vegetal ${ }^{17}$, más aún si, como en el caso que nos ocupa, coexiste el consumo doméstico con la comercialización, el auge de estos artículos en el mercado estaba jugando a favor de barrilla por poseer la referencia de la variedad más estimada $^{18}$. De hecho, aupada por los intereses internacionales, se instaló en el vocabulario de las artes de otras lenguas europeas. El caso más claro lo ofrece el inglés ${ }^{19}$. Fruto del intenso comercio durante los siglos XVII y XVIII, los británicos terminaron por adoptarla incluso en su acepción genérica ${ }^{20}$. No será hasta que la influencia de la química francesa penetre en el mundo industrial inglés a finales del XVIII cuando soda la sustituya en estos usos. En Francia, por el contrario, no traspasó los círculos comerciales y artesanales ${ }^{21}$ debido a que una producción más diversificada afianzó soude. En catalán barrella acabó

16 Cf. n. 5

17 La lengua común «est foisonnante pour les plantes utiles, absente pour les outres qui n'ont pas besoin d'être identifiée»; BIZET A. y WALTER, A. (1996), «Problématique de terminologie botanique en français: l'exemple des fruits, noix et arbres fruitiers du Vanuatu (Vanouatou)», La banque de mots, 52, pp. 31-47, p. 34.

18 No sería algo extraño en la historia de la lengua. Ciruela, por ejemplo, surgió de un proceso de este tipo.

19 Las primeras noticias de la planta y del procedimiento de elaboración de la barrilla en inglés datan de 1618: «I am now, thanks to God, come to Alicant in Spain, for I am to send thence a commodity cald Barillia for making crystal glass, and I have already treated with Signor Andriotti for a good round parcel of it to the value of $£ 2,000$. This Barrillia is a strange kind of vegetable [...] I think earthy shrub that bears berries like bar berries. When ripe they dig it up by the roots and stack it in cocks like hay to dry. When dry the place the shrubs in a track and set fire to them. The pit is closed and when after some days, it is opened, the Barillia juice is found tourned into a blue hardstone». Escrito en 1618 por James Howel. En CLOW (1992), p. 33.

20 «The Spanish soda enjoyed the best reputation and its special name barilla has been genetically used for soda made from plants». MELLOR, J.W. (1922-1937), A comprehensive teatrise on inorganic and theoretical chemistry, Londres, Longman, Green, 23 v. V. II, p. 713.

21 [Barrilla, barilla] nom qui dans le Pays \& même en France parmi les Marchands se donne encore indiferemment \& à la Soude d'Alicante, \& à la plante qui la produit», JUSSIEU, A. (1717), «Mémoire sur le Kali d'Alicant», Mémoires de l'Academie, p. 75. 
por sustituir a su predecesor parrella en todo el territorio, pero sin conseguir desbancar a sosa. En occitano barrilha tampoco lo logró.

En fin, la referencia de sosa y barrilla en contextos artesanales se caracterizaba por una gran falta de precisión. Ambas podían aludir a un tipo de plantas y a un tipo de productos distintos entre sí pero de la misma clase. Es decir, eran co-hipónimas. Por lo demás, cada una por su lado desarrolló una referencia genérica más amplia, hiperonímica, que nombraba a todo el grupo. En estos casos sosa pasaba a ser hipónimo de la barrilla, y viceversa.

Sin embargo Sebastían de Covarrubias en su diccionario de 1611 sólo consignó la acepción botánica de $\operatorname{sos}^{22}$ y barrilla carece de entrada. ¿Cómo encaja esto con la situación anterior?

\section{EL MUNDO ERUDITO: KALI, SOSA Y SAL ALKALI}

Hasta el siglo XVII el reino vegetal fue observado y descrito dentro de la tradición de la Materia médica de Dioscórides, un texto práctico y al servicio de la medicina ${ }^{23}$. Eran obras sin voluntad de ser exhaustivas, que incluían principalmente plantas con propiedades medicinales.

Como algunas de las plantas de donde se extraían cenizas, e incluso las cenizas mismas, tenían usos terapéuticos, fueron tratadas en dichas obras y, más tarde, también en las Farmacopeas oficiales ${ }^{24}$. A las «yerbas saladas» se las conocía allí con el nombre de kali, aunque también se habían utilizado otros como salsola o salicornia.

No obstante, el baremo con que las juzgaban médicos, boticarios y alquimistas era diferente al de los artesanos. Lo principal eran sus virtudes curativas porque, al fin y al cabo, en los laboratorios las podían manipular de nuevo. Esto era de hecho lo que ocurría. Las cenizas se disolvían, filtraban y evaporaban hasta obtener una sal fija, mucho más cáustica que el producto original, a la que

22 Esta es la definición: «cierta yerba de que se haze el vidrio». COVARRUBIAS, S. (1611), Diccionario de la lengua castellana o española. Consultado en CD en ÁlvAREZ DE MIRANDA, P. (comp.) (1998), Lexicografía Española Peninsular. Diccionarios Clásicos (I y II), Colección Clásicos Tavera, N 12 y 13, Fundación Histórica Tavera y Digibis.

23 Tenía descritas 600 materias vegetales. En opinión de M. Slaughter «folk wisdom put into the form of a 'how to' book», SLAUGHTER, M. M. (1982), Universal languages and scientific taxonomy in the seventeenth century, Cambridge, CUP, p. 49

24 Crosland comenta que la Pharmacopea Augustana (1653) listaba treinta. Crosland, M. P. (1978), Historical studies in the language of chemistry, Nueva York, Dover Publications, p. 91. 
llamaban sal alkali ${ }^{25}$. Sin embargo, como aún así las cenizas manifestaban propiedades diferentes se creía que su composición era distinta, aunque les reconocían un principio común, justamente esa capacidad de dar sales cáusticas.

Como quiera que los descendientes de sauda se habían integrado en los principales idiomas europeos, es lógico entonces que sosa se abriera paso en otro tipo de textos, tal como atestiguan para el español sus ocurrencias en el $\mathrm{CORDE}^{26}$. No obstante, su paso al mundo erudito se acompañó en primer lugar de una notable reducción semántica puesto que perdió su valor de hiperónimo tanto para el grupo de plantas como el de las cenizas, desempeñado por kali y sal alkali ${ }^{27}$ respectivamente. En segundo lugar, su relación con el hiperónimo de la categoría no era de tipo lógico sino ontológico.

Antes de seguir adelante, es importante recordar que la ausencia de barrilla en estos textos es igualmente significativa, más aún cuando falta en los escritos en España. Esto último es índice de dependencia científica pero, sobre todo, de incomunicación entre los sectores artesanales y eruditos del país, puesto que no debemos olvidar que Valencia era su principal productor. Sirva como contraste el ejemplo de Amatus Lusitanus quien a mitad del siglo XVI recogió la voz barrilla en su obra y la identificó como el Kali maius de otros autores (Salsola soda) ${ }^{28}$. Es decir, describió la correspondencia vigente entre planta y término en la Península.

25 «1578 Lyte Dodoens, 116 The axsen or asshes wich are made of burn kali, is called in Latin of the Alcumistes and Glassmakers Alumen Catinum but the Salte wich is made of the same Axsen is called Sal Alkali». Oxford English Dictionary (1989), Oxford, Oxford University Press. De ahora en adelante OED.

26 «E al tiempo de agora hazen el vidro de la çeniza de los arboles \& de las yervas por la fuerça del fuego; mayormente de la çeniza de la sosa se hazen muy lindos vasos \& muy claros». Fray Vicente De Burgos, (1498), traducción de El Libro de Propietatibus Rerum de Bartolomé Anglicus, una compilación medieval con 197 capítulos dedicados a hierbas y plantas. Un ejemplo más: «Vsnen, ceniça para vidrio, la sosa» ALONSO Y DE LOS RUYZES DE FONTECHA, J. (1606), Diez privilegios para mujeres preñadas.

27 En 1612 WoOdALl comenta que Paracelso «termeth every vegetable sal Alkaly». OED.

28 Amatus Lusitanus es el pseudónimo de Joao Rodrígues, portugués de origen judio que se formó en la Universidad de Salamanca y después tuvo que exilarse a Italia por las persecuciones religiosas. J. Bauhin lo citó en su obra: «kali magnum (\& Italis Soda in) Obs. Sedi medii folio, semino cochleata dicitur Lobelio. Amatus Barrilham Valentinorum vocat», BAUHIN, J. (1650), Historia Plantarum Universalis, Ebroduni, Fr. Lud. Agrafinnried. p. 702 


\section{UN MUNDO REVUELTO: PLANTAS BARRILLERAS Y SOSAS ARTIFICIALES}

Hemos visto en el apartado anterior cómo la posición de fuerza con que contaba barrilla en los ámbitos de las artes y los oficios se compensaba a favor de sosa en los círculos instruidos. Esta coyuntura se desmoronó en el siglo XVIII, aunque ya en la centuria anterior había empezado a romperse.

\subsection{Los botánicos: kalis y soudes}

A finales del s. XVI cambia el rumbo de los estudios del reino vegetal. A partir de entonces todas las plantas sin excepción merecerán análisis, descripción y un nombre ${ }^{29}$. Debido al incremento de los especímenes, la mayor circulación de las publicaciones (recientes y clásicas) y la generalización del empleo de las lenguas vernáculas emergieron graves problemas de comunicación ${ }^{30}$.

Como parte de la solución, el discurso se reorienta. A lo largo del siglo XVII se eliminan algunos temas como leyendas y creencias populares a la vez que se refuerza la descripción de la planta, centrada ahora en su estructura. También se sistematiza ésta, estrechando el paradigma léxico hábil en ella y dejándola en unas pocas frases. En paralelo empieza la búsqueda de un sistema de clasificación natural para organizar el creciente número de especies. A finales de siglo Joseph Pitton de Tournefort propone identificar todas las especies con un genus y una phrase con sus caracteres específicos, una clasificación metódica para la totalidad de los vegetales.

Hay que tener presente que esta parte estaba redactada en latín, que ya no era una lengua de comunicación corriente sino de «laboratorio» destinada a los especialistas. De hecho, el nombre popular se alejaba de las preocupacio-

29 Así lo proclamó la Enciclopedia. La botánica «a pour object la conoissance du regne végétal entier». S. V. BOTANIQUE (1765), Encyclopédie ou dictionnaire raisonné des sciences. Neufchaltel, Chez Samuel Faulche.

30 Una cita que incumbe precisamente a sosa servirá de ejemplo:

«Ay otra sal artificial que se dize sal álcali; otros le dizen sal vidrio, otros alumbre catina. Házese de la ceniza de una yerba que se dize gala o soda o dusnea. Otros la llaman diselti. En castellano se dize sosa.» B. Pérez Vargas (1569), De re metalica. En el CORDE.

$\mathrm{El}$ que todos los equivalentes se refirieran a una especie en concreto es como mínimo dudoso. Seguramente las especies a las que aludían las tres «yerbas» no eran la misma. Por lo tanto, es muy posible que quien lo escribiera o tradujera, y más quien lo leyera, no fueran capaces de identificar la realidad vegetal detrás de sosa aunque a lo mejor estuvieran familiarizados con el producto manufacturado. 
nes del botánico, pues era en la descripción biológica de la planta donde expresaba cómo la concebía.

En 1717 A. de Jussieu va a tener la oportunidad de aplicar el patrón de Tournefort en una memoria sobre la barrilla fina, que había conocido durante su viaje por España. En ella el francés describe tanto la planta como el producto de su lejivación. A la primera la clasifica dentro del género Kali y la distingue de las demás de su grupo con la frase Hispanicum supinum, annuum, sedi foliis brevibus.

Al principio asegura que es la primera descripción de la misma, pero más adelante revela que Amatus Lusitanus pudo haberla conocido bajo el nombre de barilla, barille en francés, y comenta que así se designaba planta y producto en el comercio galo. También admite que Tournefort reparó en ella durante su viaje a Levante sin que llegara a más. Se trataba, pues, de una planta identificada pero no descrita.

Nada de esto fue obstáculo para que intentara enmendar su denominación en las lenguas vivas, al descubrir la gran confusión léxica que reinaba en el grupo de las plantas marítimas saladas. A su juicio soude resultaba equívoco y vago ${ }^{31}$. Era vago porque remitía tanto a la sal como a la planta; era equívoco porque plantas de distinto género recibían el mismo nombre. Esto último era bastante reciente.

Joseph Pitton de Tournefort había escindido en dos géneros la serie de $\mathrm{Ka}$ lis. A uno de ellos le dejó el mismo término. Al otro en 1703 ya lo había bautizado como Salicornia, reciclando un término ya utilizado por Dodoneus, que no era desconocido en francés porque en Narbona se conocía a una de sus especies con este nombre. Sin embargo, salicor aparecía como sinónimo de soude en obras de referencia muy populares ${ }^{32}$, lo que indujo al error a algunos

31 Años después la Enciclopedia aún se hacía eco de ello: «Les botanistes n'ont éclairé jusqu'a présent qu'imparfaitement cette partie \& nous trouvons si peu d'ordre \& de clarté dans les noms \& les descriptions qu'ils donnent des plantes dont on a coutume de tirer la soude, que nous n'osons en présenter un tableau complet, [...]»; Encyclopédie (1765), S. V. SoudE.

32 Mencionan la sinonimia entre soude y salicorne J. Bauhin (1650), p. 704-705; P. Pomet: «Nous vendons à Paris de quatre sortes de soudes, à qui les anciens ont donné le nom de salicore, ou salicote, ou d'Alun Catin [...]»; POMET, P. (1694), Histoire generale des drogues, París, Chez Jean Baptiste Loyson \& Augustin Pillon, p. 168. Despuès, esta información traspasó a los diccionarios de lengua. V. en el apéndice I, la entrada kali del diccionario de Trévoux. Dictionnaire universel François et Latin, vulgairement appelé Dictionnaire de Trévoux (1704) París, Compagnie des Libraires Associés. Catel escribió la historia de Llanguedoc en 1663. Unos años más tarde Lémery aún recordaba la antigua afiliación de la salicornia diciendo que «Est un 
autores posteriores que las consultaron y, despistados por la vieja sinonimia, no atinaron a identificar correctamente una y otra, como les sucedió a Guyton de Morveau, Maret y Durande 33 .

De ahí la urgencia de Jussieu por cambiar el nombre popular para la planta: difundir a círculos más amplios la nueva partición genérica requería distinguirla también en la lengua común para así zanjar los errores y malentendidos que el uso de los nombres populares perpetuaba.

Con este objetivo en mente decide aprovechar el nombre científico del género botánico kali, mientras que los productos, por el contrario, deberán ser conocidos todos con el mismo nombre, soude, que ya poseía valor genérico. Además, como sus subclases también llevarán el mismo término, su emparentamiento quedará verbalizado. De este modo, la especie de Alicante que acababa de describir se llamará a partir de entonces Kali d'Alacant y Soude d'Alacant será su producto; el varech dará soude de varech, etc.

Al menos en francés, la medida significaba la supresión de barrilla. A cambio, sólo acarreaba la modificación del espectro semántico de soude al normalizar su valor como hiperónimo. Por último, Jussieu dio entrada a un neologismo de forma y sentido, kali, filtrado de la lengua de laboratorio de los «metodistas», cuya forma fonológica y gráfica resaltaba su exogenia.

Como es de suponer, los artesanos permanecieron impasibles a los cambios. Sin embargo Jussieu logró sus objetivos a largo plazo, aunque más en el fondo que en la forma, ya que Linneo sustituyó Kali por Salsola y después el género fue remodelado de nuevo. En cambio, en los círculos químicos su medida logró una mayor repercusión. Ya fuera por la admiración de ciertos sectores hacia la normalización terminológicas de los botánicos, ya fuera por propia conveniencia al ser sosa una voz presente en sus textos, lo cierto es que primero kali $^{34} \mathrm{y}$ después salsola ${ }^{35}$ reemplazaron efectivamente al rosario de nombres más o menos locales de las plantas saladas.

petit arbrisseau ou une plante qui a été toujours du nombre des Soudes», p. 769. LEMERY, N. (1733), Dictionnaire Universel des Drogues Simples, París, Laurent d'Houry.

33 Los autores afirman que «le salicor» que crece a orillas del mediterráneo es el «kali majus cochleato semine», o sea, la Salsola soda. GuYton DE MorveAu, L. B., MARET, H. y DURANDE, J. F. (1777-1778), Éléments de chimie rangés dans un nouvel ordre, Dijon, impr. de L.-N. Frantin, p. 199.

34 MACQuer, P. J. (1766), Dictionnaire de chymie, París, Chez Lacombe: «la combustion de plantes marines du genre des kalis», p. 88; «les cendres son connues dans le commerce, sous le nom de soude», p. 94.

35 Hablando de la soda, Brugnatelli explicaba que «La pianta che di ordinario serve a questo scopo è la Salsola soda Lin. VAUQUELIN, [...] In Spagna, sopratutto nelle vicinanze del 
Con independencia del respaldo que consiguió Jussieu, es importante tener presente que a través de su propuesta estaba respondiendo a cuestiones que serán claves en las discusiones lingüísticas de la Ilustración: la arbitrariedad del signo, los niveles funcionales de lengua y la relación de poder entre disciplinas científicas, o de éstas sobre el pueblo, bajo la forma de imposiciones léxicas. Cuando hubo que adaptar en español la terminología de la botánica moderna, nuestros ilustrados tuvieron que contestar a las mismas preguntas.

\subsection{Los químicos: alkalis y soudes}

No es extraño que fueran los químicos los que más se aprovecharon del nuevo reparto referencial entre soude y kali. A ellos, que también habían empezado su andadura hacia la normalización terminológica, les afectaba por igual la colisión de acepciones de sosa. Ésta ocurría naturalmente en los contextos que describían las fuentes de extracción de los álcalis o la fabricación del vidrio y el jabón. Conforme avanza el siglo, la distinción léxica entre planta y producto revela su acierto, porque deja vía libre a la posterior terminologización de sosa en la nomenclatura química.

Cuando las investigaciones de Duhamel (1736) y Black (1755) reconceptualizaron la clase de los álcalis parcelándola en nuevas divisiones y subdivisiones ${ }^{36}$, ambos lo expresaron expandiendo el término genérico con sucesivas especificaciones adjetivas: alkali-alkali fixo-alkali fixo mineral o marino - alkali fixo mineral cáustico. La inviabilidad de las últimas salta a la vista.

Su situación empeoró al imponerse en la disciplina criterios de denominación conforme la composición de las sustancias. Cuando una sal tenía una base alcalina, como en nitro a base de álcali fixo mineral (nitrato de potasa), nombrarla entera resultaba extenuante, no digamos redactar un texto. Por esta razón los sintagmas plenos sólo aparecían en los títulos, escaseando en el

\footnotetext{
Alicante, se ne prepara in gran quantitá, ed è forse la migliore: la pianta che la soministra chiamasi barrilla la quale non è altro, che una specie de Salsola. Se ne cava pure della Salicornia e da altre specie di Atyepeci»; Brugnatelli, L.V. (1800), Elementi di Chimica, Venecia, con privilegio, 3 vols., II, p. 100. Berzelius se limitó a apuntar que la mayoría proviene de los género Salicornia y Salsola y que de entre ellos la Salsola soda y la Salsola kali son las que se explotan con preferencia. Berzelius, J. (1830), Traité de chimie, París, Didot, 8 vols.

36 Duhamel du Monceau distinguió dos tipos de álcalis fijos, uno vegetal (la potasa) y otro marino o mineral (sosa). Margraff confirmó sus resultados en 1761. J. Black relacionó los dos estados (dulce y cáustico) de los álcalis con la presencia del ácido carbónico.
} 
cuerpo de la obra. El propio Black (1803) los reprobó a posteriori por «cumbersome and desagreable» ${ }^{37}$.

Como remedio a estos problemas estilísticos, lo más normal era recurrir a una elipsis y dejar que el contexto supliera la información suprimida. No obstante, era una práctica desaconsejada porque en ella anidaba la vaguedad. Otra alternativa era utilizar un sinónimo. Para el álcali fijo mineral soude era la mejor opción una vez que el otrora popular tartre se quedara en el grupo de los álcalis vegetales. El otro candidato que parecía desprenderse de la memoria de Duhamel base du sel marin tenía el mismo problema que alkali fixe mineral/marin. En la década de los setenta, la identificación con sosa es ya muy fuerte ${ }^{38}$.

De esto se valió Guyton de Morveau para sugerir la sustitución de alkali fixo mineral por el artesanal soude en la «Mémoire sur les dénominations chimiques» de $1782^{39}$. Al otro alkali fixo, el vegetal, lo llamó potasse, que había experimentado un proceso de terminologización paralelo a soude. Decía cumplir así su promesa de no incomunicar la química de otras disciplinas colindantes, con un vocabulario extraño. Cinco años después, sus compañeros en la redacción del Méthode de Nomenclature, Lavoisier, Berthollet y Fourcroy, apoyaron esta medida.

Sin embargo, su elección se interpretó menos como un gesto conciliador con el mundo de las artes que como un paso atrás en el avance de la química por culpa de la polisemia que comportaba. Por esta razón, desde 1782 hasta la primera década del siglo XIX se presentaron numerosos pretendientes alternativos a los puestos de los álcalis fijos ${ }^{40}$.

37 BLACK, J. (1803), Lectures on the elements of chemistry, Edinburgh: Creech, p. 488.

38 «La soude est la cendre d'une plante qui porte le même nom: elle contient une très grande quantité d'alcali marin \& alkali végétal», BAUME, A. (1763), Manuel de Chimie, Paris, Didot, p. 28; el mismo autor, diez años después afirma que al álcali fijo mineral «on nomme aussi alkali marin \& alkali de la soude» BAUME, A. (1773), Chymie expérimentales et raisonnée. Paris: P.F. Didot, 2 v., vol I p.23; BergmAn, T. (1775), «Commentatio de acido Aereo», Nova Acta, Ser. 2, 1, pp. 108-125, «Alkali fixum, quod minerale audit, vel etiam vulgo sal sodae vocantur», p. 122.

39 V. Guyton de Morveau, L. (1782), «Mémorie sur les dénominations chymiques» en Observations sur la Physique, 19-1, pp.370-382. En especial las páginas 378-379.

40 R. Chevenix hizó un recuento de los candidatos propuestos en el Reino Unido en CheVenix, R. (1802) Remarks upon chemical nomenclature. Antes de que Klaproth lograra que la comunidad alemana los aceptara, natrón, que sobrevivía en el vocabulario de la mineralogía, ya había sido propuesto por Bergman en 1784. B. Sage lo prefirió también y, tras la reforma de 1787 de la Métherie, lo reivindicaría de nuevo. Convencido por las razones del francés, el gaditano Juan Manuel Aréjula lo eligió para el español. 
De hecho, tanto la decisión de Guyton como las reacciones posteriores pueden considerarse una nueva instancia del debate sobre las fuentes de la lengua científica. Guyton revivió el dilema de Jussieu al tener que decidirse entre un neologismo de forma y uno de sentido. En el primer caso favorecía la comunicación entre especialistas; en el segundo acercaba sectores sociales. Él, al contrario que el botánico, se inclinó excepcionalmente en esta ocasión por la segunda opción.

¿Y barrilla? El siglo XVIII fue el momento de máximo esplendor de su exportación a Europa. Como es lógico, la presencia de la voz fue general en las obras químicas de la centuria. Al abordarse los usos y las fuentes del álcali mineral surgía inevitablemente el nombre de barrilla, pero siempre en referencia a esa variedad tan apreciada cultivada en Alicante. En las artes fija su posición hiponímica respecto a sosa, con un significado que podría parafrasearse como «sosa de primera calidad». En conjunto puede decirse que ambas asientan su referencia con respecto a las vacilaciones de años atrás.

Luego, las reformas de los años ochenta no hacen sino consumar su descarte de la terminología química. La memoria de Guyton superpuso a ambas palabras una nueva relación conceptual, esta vez de tipo ontológico, al ser la sosa uno de los componentes de la barrilla. Sosa se hará omnipresente en los textos a partir de entonces, ambigua y polisémica a pesar de la voluntad de los reformadores, como lo prueban las expansiones terminológicas que desarrolla a partir de entonces (sosa común, sosa del comercio, sosa cáustica). A barrilla le queda la mención anecdótica en el apartado dedicado a la preparación y, con suerte, la aplicación de la sosa en las artes ${ }^{41}$. Una vez los métodos de Solvay y de Leblanc coparon el mercado de sosas artificiales, ni eso.

Sin embargo, los hombres de ciencia se equivocaron al creer que era posible imponer sus dictados en cuestiones lingüísticas y modificar los hábitos de los hablantes fuera de los círculos especializados. Así lo corroboran las constantes aclaraciones de los manuales de química para uso en las artes ${ }^{42}$ o el mantenimiento durante todo el siglo XIX de una entrada para barrilla, con acepciones para la planta y las cenizas, en diccionarios generales y especializados ${ }^{43}$.

41 «Soda is commonly obtained from the ashes of plants growing on the sea shore, particulary from a genius called salsola, in Spain, where this article is largely prepared, it is called barrilla». DALton, J. (1808), A new system of chemichal philosophy, Londres, Russell \& Allen.

42 «La soude d'Alicant est connue sous le nom de barille, c'est à dire le nom de la plante qui la fournit» CHAPTAL, J.A. (1807), Chimie appliquée aux art, París, Deterville, t. II, p. 130.

43 Klaproth, M H. y Wolff, F. (1810-11), Dictionnaire de Chimie, París, Klosterman; LARousse, P. (1866), Gran dictionnaire universel (1867), París, Larousse. 
Recapitulemos. El propósito con que emprendieron unos y aceptaron otros las modificaciones en el léxico de la plantas saladas y sus productos fue el de conseguir un término genérico distinto con el que evitar inexactitudes y ambigüedades. A poder ser, los candidatos tampoco deberían coincidir con ninguno de los de su subclase, pero, sobre todo, no podían entorper la expresión de los cambios acaecidos en la reconceptualización de la categoría.

Al interrogante de cuáles eran las fuentes léxicas más apropiadas a tal efecto responden proponiendo los cultismos salicornia y kali, luego salsola, para las plantas. Después cada lengua vernácula tendría que naturalizarlos. En cambio, para las cenizas respetan la voz popular vigente en las artes, aunque el progreso de la ciencia la iba alejando cada vez más de su referente primigenio. El empleo de otras voces quedaba descartado en virtud de la comunión internacional que quería alcanzarse en el lenguaje científico.

\subsection{La respuesta en España: barrilla y sosa}

En España, la reordenación léxica de plantas y productos empezó ya entrado el siglo XVIII, a raíz de la introducción de la práctica botánica moderna que estaban llevando a cabo los sectores ilustrados del país ${ }^{44}$. Por otra parte, el que sosa y barrilla hicieran referencia a una realidad cotidiana provocó que dicha labor la asumieran tanto los interesados en la práctica científica como en su divulgación al público culto.

En este segundo grupo hay que incluir el primer diccionario académico, llamado de Autoridades (1726-1739), y el Diccionario castellano: con las voces de ciencias y artes de Sebastián Terreros, publicado en 1786-1793, pero redactado ya antes de 176745 . Sus soluciones, pese a ser deficientes, manifies-

44 Como referencia general del estado de la ciencia en la Ilustración, véase SELLÉs, M., Peset, J. L. y LAfuente, A. (coords.) (1988), Carlos III y la ciencia de la Ilustración, Madrid, Alianza Universidad; Fernández Pérez, J. y GonzÁlez TAscón, I. (eds.) Ciencia, técnica y estado en la España ilustrada, Zaragoza, Ministerio de Educación y Ciencia, Secretaría de Estado de Universidades e Investigación. Para la botánica, PuERTo SARMiENTO, F. J. (1988), La ilusión quebrada, Madrid, CSIC.

45 Consultados en los CDs de Lexicografía Española Peninsular (1998). Es bien sabido que el primer diccionario académico de 1726, se planteó seriamente el tema de la relación entre el léxico facultativo y el general, aunque después lo aparcara con la promesa de un futuro diccionario de voces técnicas. Sobre estos dos diccionarios, véase ÁlvAREZ DE MIRANDA, P. (1992), «En torno al diccionario de Terreros», Bulletin Hispanique, 94-2, pp. 559-572; AZORÍN FERNÁNDEZ, D. (2000), Los diccionarios del español en su perspectiva histórica, 
tan una clara voluntad de sentar criterios propios para la fijación de un vocabulario científico español.

Autoridades, que aún participa de la visión unitaria del grupo de las plantas saladas, traslada ese kali culto, francés e internacional a la vez, como alkali, a pesar de que éste no falte en la macroestructura con una remisión ( $v$. las entradas de los dos diccionarios y el de Trévoux en el Apéndice I). Es decir, optaron por ampliar el significado de un término culto ya en uso, porque la acepción vegetal de alkali, si es que existió, era de lo más insólita.

A Terreros le corresponde el mérito de querer aclimatar al español los géneros tournefortianos Kali y Salicornia. El padre jesuita muestra una vez más su independencia respecto al modelo académico, enfocando diferentemente el problema de la expresión de los progresos científicos. Cuando juzga que el idioma carece de voz no tiene reparos en acudir al latín salicornia, que ajusta como salicornio por intermedio del francés ${ }^{46}$. En cambio, kali y alkali no le merecen más que una referencia cruzada a sosa porque, con una voz patrimonial aludiendo a la misma realidad, elegir una voz extrajera clásica o moderna sólo alejaría a los instruidos de la ciencia.

En la redacción de este artículo en particular es posible que intervinieran indirectamente José Quer o Miguel Barnades. El pormenor de la información que se agolpa al final de la entrada, con el aire de un añadido, me hace sospechar que hubiera podido consultarlos, tal como asegura en el Prólogo ${ }^{47}$.

Ciertamente, los dictámenes de ambos diccionarios encarnan la postura de sus responsables sobre las relaciones entre lengua científica y lengua vulgar. Autoridades se inclina por cortar cables entre ellas, Terreros por acercarlas. Para éste último los tecnicismos son parte integrante de la lengua común y el castellano un material apto con que darles cuerpo. Sus divergencias reproducen a pequeña escala la polémica ilustrada acerca de qué lenguaje era el mejor para expresar y divulgar la ciencia.

\footnotetext{
Alicante, Universidad de Alicante. En especial los capítulos 6, 7 y 8. La introducción de la nomenclatura química en el diccionario académico ha sido tratada en varias ocasiones por Cecilio Garriga Escribrano. Los trabajos de Juan Gutiérrez Cuadrado sobre la historia del léxico especializado en los siglos XVIII y XIX aluden también a la difusión de tecnicismos en obras lexicográficas. Puede obtenerse bibliografía de ambos en GARRIGA, C. et al. (2001), «Proyecto: la formación de la terminología química en español» en BRUMME, J. (ed.) La historia de los lenguajes iberorrománicos de especialidad, Barcelona, Vervuert, pp. 105-118. catalán.

$46 C f$. con salicor, la forma que incorporó el castellano, que corresponde al préstamo del

47 Prólogo, p. VIII-IX.
} 
Sin dejar de tener presente lo anterior ni desmerecer su apuesta por la introducción de términos y definiciones científicas es forzoso lamentar su poco oído, porque si bien el significante ya existía el significado era nuevo. Muy pendientes de sus fuentes francesas, se echa de menos una comprensión más profunda y global de los cambios en la conceptualización del campo. En ambas obras el artículo de barrilla parece el pariente pobre del grupo. Destaca sobre manera que ninguno de ellos constatara la acepción de producto ${ }^{48}$, que sí consta en sosa, cuando su comercio estaba en el máximo apogeo. Finalmente, quizá confiados por una equivalencia latina que no le correspondía (parietaria), tampoco se percataron de su identidad con sosa, ni de que la barrilla pertenecía al género kali.

Hay que añadir además que Terreros, ya fuera confundido por sus fuentes $^{49}$, ya arrastrado por otras decisiones, ya por falta de referentes, emparejó la Salicornia europea con el nombre de soda y la Salsola soda con salicornio. Es decir, las intercambión ${ }^{50}$. Realmente, las quejas de Clavijo y Fajardo sobre «la confusión en todos los Diccionarios, aún los más acreditados, en cuanto a las correspondencias Castellanas de las voces latinas y Francesas de la Historia Natural» cobran sentido a la vista de tales artículos ${ }^{51}$.

En la segunda mitad de XVIII los botánicos les tomaron el relevo y afrontaron de nuevo la cuestión. Desde el Real Jardín Botánico de Madrid J. Quer, M. Barnades, J. Minuart, C. Gómez Ortega, A. Palau Verdera y J. Cavanilles llevaron a cabo puesta al día en la descripción, clasificación y denominación de las plantas autóctonas que publicaron en compilaciones más o menos actualizadas en lo científico ${ }^{52}$. En 1804 la institución inició una nueva etapa con

48 Este descuido sobresale en especial en Autoridades, porque justo del ejemplo que acompaña la definición se desprende el sentido de barrilla como producto.

49 Vid. n. 32.

50 Sólo de esta manera tienen sentido sus afirmaciones de que «el salicornio» sea mucho más útil que «la barrilla» para la fábrica de cristales o que ésta última sea «defectuosa» sin la sosa.

51 Prólogo del traductor p. III y IV en Buffon, G. L. COMTE DE (1785), Historia Natural general y particular, Madrid, Ibarra, 21 v., citado en GÓMEZ DE ENTERRÍA, J. (1998), «Consideraciones sobre la terminología científico-técnica de carácter patrimonial en el español del siglo XVIII» BRAE, 78, pp. 276-301, p. 280.

52 La Flora española de J. Quer (1762-64) sigue el sistema de Tournefort; los Principios de Botánica de M. Barnades (1767), el sistema linneano. La generalización definitiva del sistema del sueco llegó en la década de los ochenta tras un periodo ecléctico representado por las primeras obras de C. Gómez Ortega y A. Palau Vardera, ambos profesores del Real Jardín Botánico. V. Lafuente, A.; Puig-Samper, M. A.; Hidalgo CÁmara, E.; Peset, J. L.; PelaYO, F. y SELLÉS, M. (1996), Historia literaria de España en el siglo XVIII, Madrid, CSIC. 
la entrada de Francisco Antonio Cea a la muerte de Cavanilles, pero para entonces la decisión acerca de cómo debían llamarse en español salsolas y salicornias ya había sido tomada.

A pesar de que un punto de partida distinto su respuesta les alinea en lo lingüístico con Terreros. Al igual que el jesuita prefirieron acudir a formas patrimoniales para la organización del campo. Pero ellos, con un conocimiento más completo optan por barrilla para las Salsolas ${ }^{53}$. Quizá tuviera que ver que muchos de ellos, pese a estar vinculados profesionalmente a la farmacia, tuvieran fuertes lazos con la zona de Levante (Quer, de Perpignan, herborizó Cataluña y Valencia; Minuart y Barnabés era catalanes y Cavanilles valenciano); pero lo que interesa aquí es que lograron cristalizar en el léxico la distinción entre el producto y la planta sin buscar en otras lenguas ${ }^{54}$. Con ello demostraron una conciencia lingüística muy viva, característica de la Ilustración.

El influjo de la botánica, claro está, también se dejó notar en dominios colindantes como la química. Como hicieran sus colegas europeos, los españoles actualizan la terminología de sus libros y traducciones. Un buen ejemplo de esta puesta al día lo proporciona la versión española de los Elementos de Química teórica y práctica de Morveau, Maret, Durande a cargo de Melchor de Guardia y Ardèvol.

El traductor sigue fiel al original cuando traduce los productos derivados de la combustión de las plantas pero se aparta en cuanto debe trasladar el nombre de las plantas proveedoras de sosa. A diferencia de Terreros, Guardia

53 CAVAnilles, J. (1795-97), Observaciones sobre la historia natural, geografia, agricultura, población y frutos del reyno de Valencia, Madrid, Imprenta Real. «En las arenas y sus cercanías crecen muchas plantas, entre las quales hallé tres nuevas, que son la ipomea asaetada, la agróstide que punza, y la poa marítima: es comun el senecio doria, la genciana espigada, los tártagos peplis y paralias, la correhuela de mar, la salicornia leñosa, las barrillas de Alicante y tragus, el lenitisco, el torbisco y otras muchas.» En el CORDE. Las páginas de Internet también confirman el triunfo de su proposición.

54 Hernández de Gregorio expuso el reparto léxico para sosa y barrilla con razones muy parecidas a las esgrimidas por Jussieu casi cien años antes: " Hasta ahora se extraía la sosa solamente de una planta, que Linneo llama salsola tragus, y en castellano kali sosa ó barrilla, de donde ha tomado el nombre; pero como se ha extraido posteriormente de muchas plantas que crecen en las orillas del mar, llamadas por esta misma razón plantas marítimas, como la salicornia y otras especies de la salsola, ha sido preciso sustituir el nombre de sosa, para significar de una vez así esta sal de barrilla, como de otra cualquiera planta marítima que tenga las mismas propiedades, y de borrar de una vez tantos nombres distintos que se aplican a una misma cosa» HERnÁNDEZ DE GREGORIO, J. (1798), Diccionario elemental de farmacia, Madrid, Imprenta Real, 2 vols., t.II, p. 88 
y Ardèvol no cae en la trampa y rectifica el salicor del original francés con el término linneano Salsola soda en todas las ocasiones ${ }^{55}$.

Los diccionarios también dieron cabida en sus páginas a la normalización terminológica orquestada por los botánicos. En 1770-1783 barrilla gana en precisión descriptiva sin que varíe sustancialmente el resto; sosa en cambio permanece igual. En 1803 entra en el diccionario salicor y al cabo de catorce años la nomenclatura linneana reemplaza las paráfrasis latinas. En esta edición, barrilla sufre una reestructuración completa. Se le otorgan cuatro acepciones, todas definidas con lenguaje técnico: la primera es para la Salsola soda; la segunda, para las cenizas; la tercera y la cuarta son las lexías barrilla borde y la barrilla de Alicante a las que corresponden los términos linneanos Salsola tragus (hoy Salsola kali subs. Tragus) y Salsola sativa (hoy Halogeton sativus), respectivamente. Más tarde los suprimieron, pero la organización y definición de barrilla se ha mantenido sin grandes cambios. Desde 1899 el artículo de sosa sólo define la acepción química del óxido de sodio, las demás remiten a barrilla.

De hecho, la química dieciochesca española no mostró interés alguno por arrebatar a sosa este último sentido en favor de barrilla, pese a que podían haber encontrado sin dificultad argumentos para ello. A principios de siglo, el boticario Félix Palacios colocó una al lado de la otra en su traducción del Curso de Química de N. Lémery ${ }^{56}$; mientras lo acababa, J. M. Aréjula en las Reflexiones sobre la reforma de la nomenclatura química (1788) ni siquiera se planteaba que barrilla fuera alternativa a soude, que consideraba inconveniente ${ }^{57}$.

Hasta el momento no he encontrado ningún indicio de reivindicación de barrilla para estas funciones. Más bien al contrario, todas las traducciones al español de la sinonimia entre la vieja y la nueva nomenclatura del Méthode la añaden, pues estaba ausente en el original, pero como equivalencia del carbonato de sosa. F. Carbonell y Bravo hará lo propio en la edición castellana de los Elementos de Farmacia en 1805. Es claro que en su contra habían actuado su especialización en la terminología botánica, el arraigo secular de sosa en la

55 «La salsola soda crece á orillas del mediterráneo (kali maius cochleato semine)» GuYTON De Morveau, L. B., MARET, H. y Durande, J. F. (1788), Elementos de Química teórica y práctica, Madrid, Imprenta de Benito Cano, p. 459.

56 Este dato lo conocí de forma indirecta en la reproducción de la tabla que ofrecen GARCía Belmar, A. y Bertomeu SÁnchez, J. R. (1999), Ilustración IV. 6, p. 71. No sé por lo tanto si Félix Palacios lo utilizó en el cuerpo del texto.

57 V. n. 40. Aréjula en cambió reivindicó el patrimonial alabandina como traducción de manganèse. 
disciplina y el peso de la química gala. Desde entonces, si ha de aparecer barrilla en un manual de química, siempre lo hará en el capítulo dedicado a las sales definidas como carbonato sódico impuro.

Por otra parte, la comunidad científica española tampoco fue una excepción en lo concerniente a eliminar el significado popular de soda y de barrilla. Es cierto que algunos autores muy en contacto con la ciencia vecina, como S. Francisco y Garriga, cumplieron los dictados franceses y hablaron de la sosa de Alicante en vez de barrilla. Otros, como el mismo Carbonell y Bravo ${ }^{58}$, infiltraron el esquema galo al completo en sus traducciones o adaptaciones al español. Es decir, aludieron a barrilla como la planta o el producto de la Salsola sativa en exclusiva. Ésta no era una atribución falsa, pero sí inexacta.

Con todo, fueron los menos. Barrilla subsistió en el mundo del comercio, tal como certifica su puntual mención en los manuales de química a lo largo del siglo XIX, con cierta preferencia por asociarla a los productos naturales. Para los industriales se tendía a reservar $\operatorname{sos}{ }^{59}$. Es comprensible entonces que su mención vaya trasladándose hacia apartados dedicados a la historia de la disciplina. De todos modos, no es una raíz muerta para la ciencia. A la acepción vegetal ya apuntada hay que añadir el adjetivo de relación barrillero, de uso restringido pero especializado, y aún hoy vivo en la colocación plantas barrilleras ${ }^{60}$.

\section{CONCLUSIÓN}

De todo lo expuesto podemos concluir que en español se superponen en las voces barrilla y sosa tres parcelamientos semántico-conceptuales: uno

58 Chaptal, J. A. (1816-21), Química aplicada á las artes, Barcelona, Imprenta de Brusi, 4 vols., t.II p. 72.

59 CASARES, A. (1857), Manual de química general, Madrid, Librerías de Ángel Calleja, ilustra lo más típico en los manuales: «En las costas del Mediterráneo, principalmente hacia Málaga, Alicante y Cartagena, crecen plantas del género Salsola llamadas barrilla. [...] Esta misma masa [la que queda después de secar y quemar las plantas] corre en el comercio con el nombre de barilla», p. 233; «El valor de las potasas, barrillas, sales de sosa y sosas brutas que corren en el comercio, varía según la cantidad de álcali libre o carbonato que tienen».

60 En internet se encuentran numerosas páginas que contienen el adjetivo barrillero/a: «La barrilla, obtenida de diversas sosas barrilleras que crecían en los saladares y utilizada en la fabricación de vidrio y jabones, daba lugar asimismo a un floreciente comercio que sólo se vería afectado por la fabricación de productos químicos alternativos en el siglo XIX» en http://www.ub.es/geocrit/b3w-6.htm. 
popular, otro especializado patrimonial y un tercero especializado, pero extranjero, más minoritario. Esta triple superposición semántica es el resultado de un proceso histórico en el que influyeron, además del progreso de la ciencia, el lenguaje de diferentes naciones y el de diferentes clases de personas. Además, el seguimiento de dicho proceso ha desvelado que el cambio terminológico suele ser la culminación de un proceso incubado desde tiempo atrás, incluso cuando se presenta como súbito.

Así mismo hemos podido comprobar cómo las llamadas al orden hechas por los expertos en lengua y en ciencia para racionalizar las correspondencias entre un concepto y su término son luego incumplidas por unos y otros sin excepción, y la comprensión del mensaje no se resiente. Esto último nos lleva a reflexionar sobre la sinonimia y la polisemia terminológica. La fusión en los textos, también en los especializados, de diferentes estratos lingüísticos (geográficos, funcionales, históricos, teóricos) se concreta en el empleo de sinónimos parciales como recurso estilístico que en un momento dado puede amenizar el escrito e, incluso, desambiguar otro término polisémico. Es factible hablar entonces de una terminología en la sombra que surten esos otros niveles de lengua. Ésta, ausente de las nomenclaturas oficiales, pero viva en la literatura, se caracteriza por estar pendiente de la actualización contextual para conseguir un significado, de ahí la dificultad de definir sus miembros, frente a la relativa autonomía contextual que disfrutan los verdaderos términos. Sosa y barrilla pertenecerían a este grupo.

Finalmente ha dejado claro que en la formación del léxico científico español el XVIII fue el siglo de decisiones que sentarían precedente, de pruebas y de rectificaciones. Si el XIX fue el del levantamiento de ese edificio, sus cimientos se echaron en el siglo anterior. En este sentido, con esta aportación espero haber colaborado a demostrar la importancia de los estudios sobre la formación y desarrollo del lenguaje especializado para conocer el camino por el que transcurrieron, y transcurren, la lengua y la ciencia. 


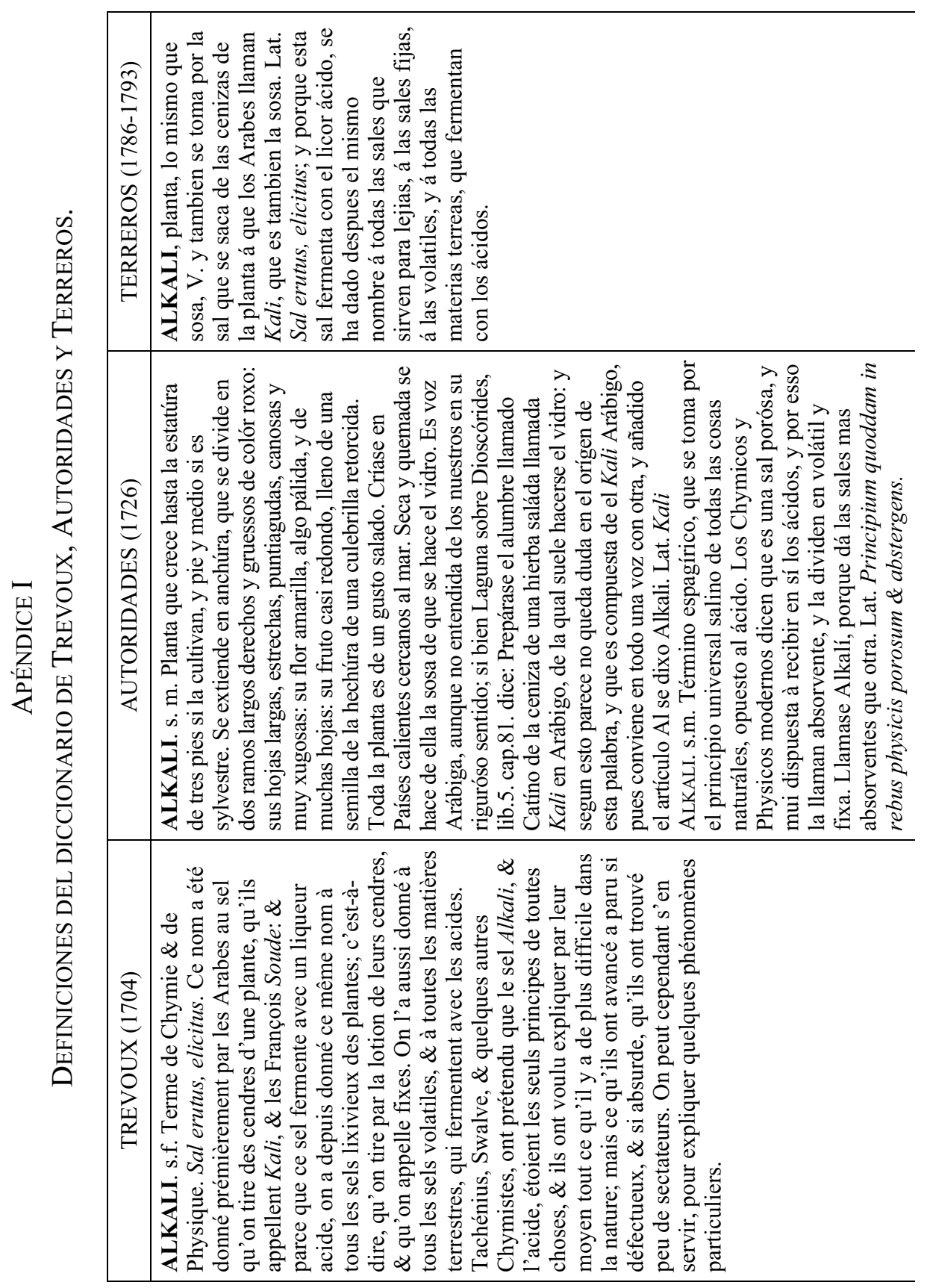




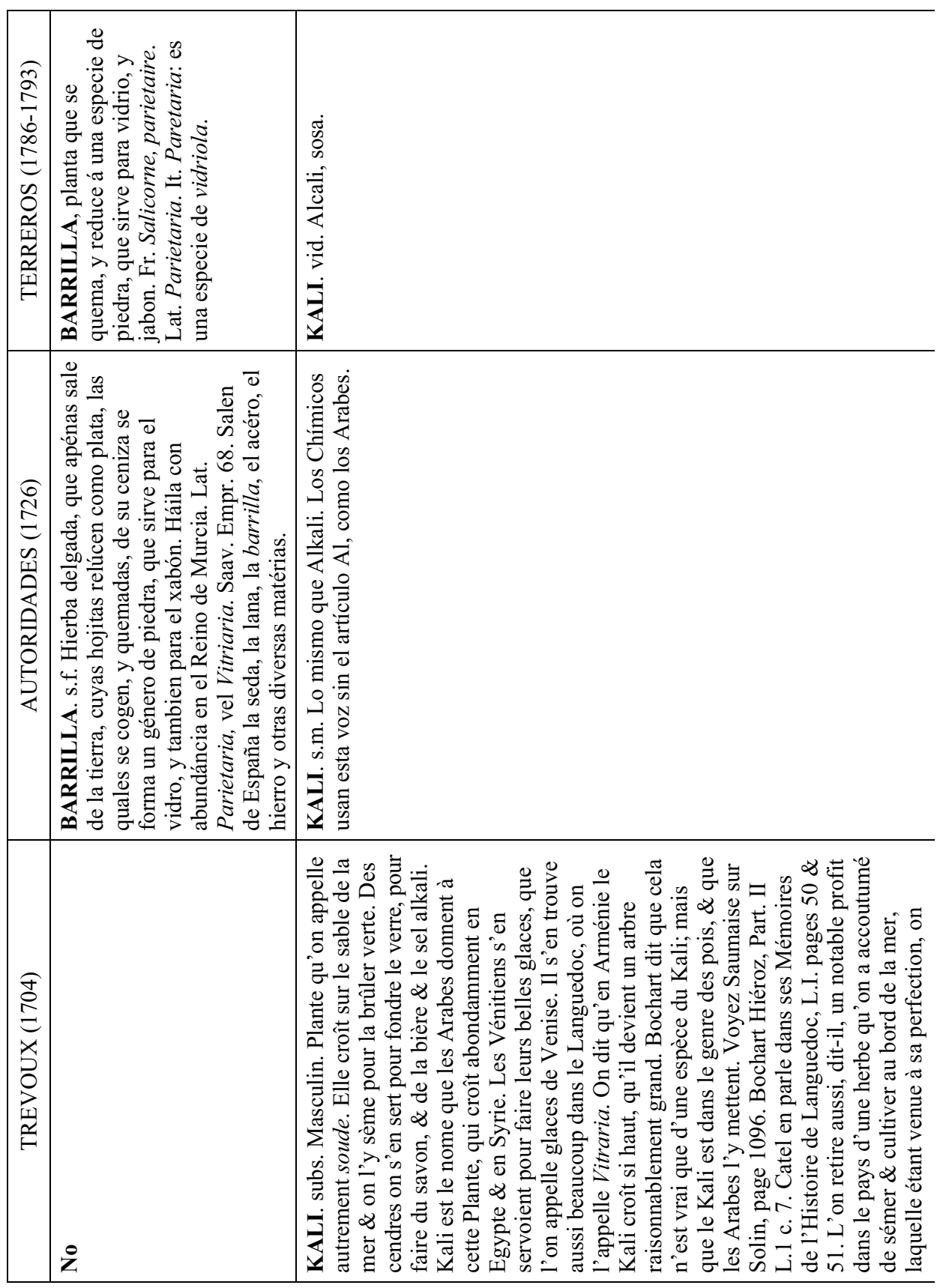




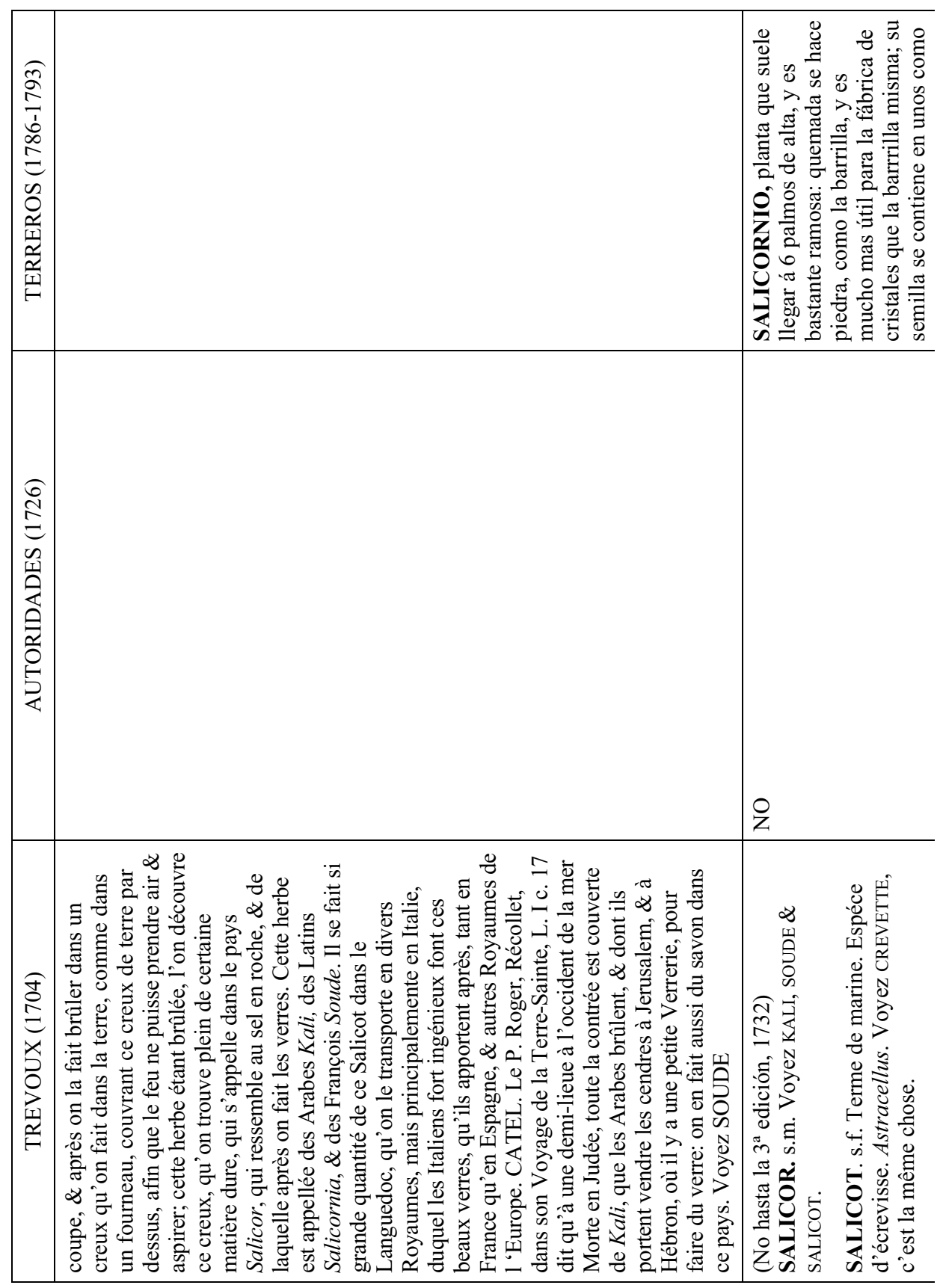




\begin{tabular}{|c|c|c|}
\hline 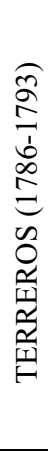 & 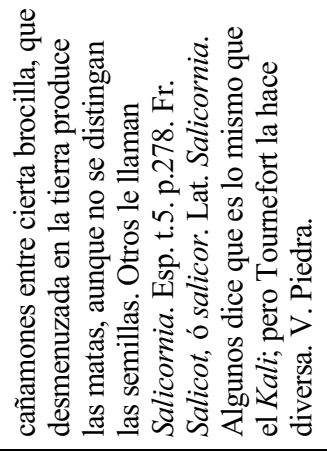 & 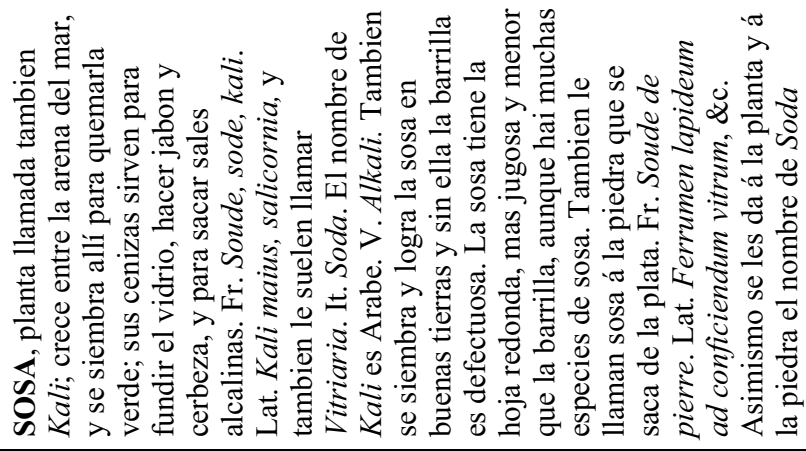 \\
\hline 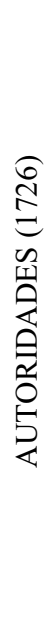 & & 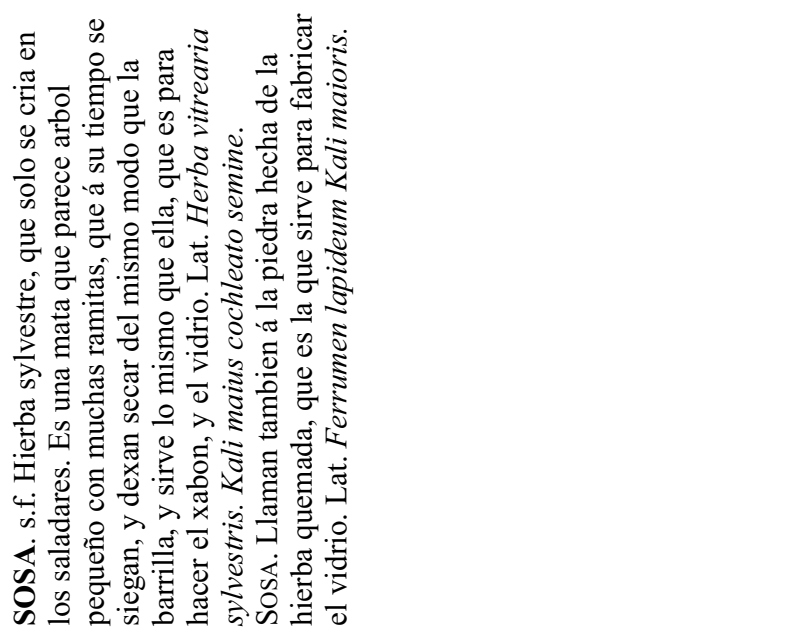 \\
\hline 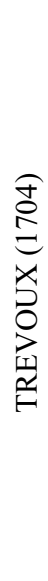 & & 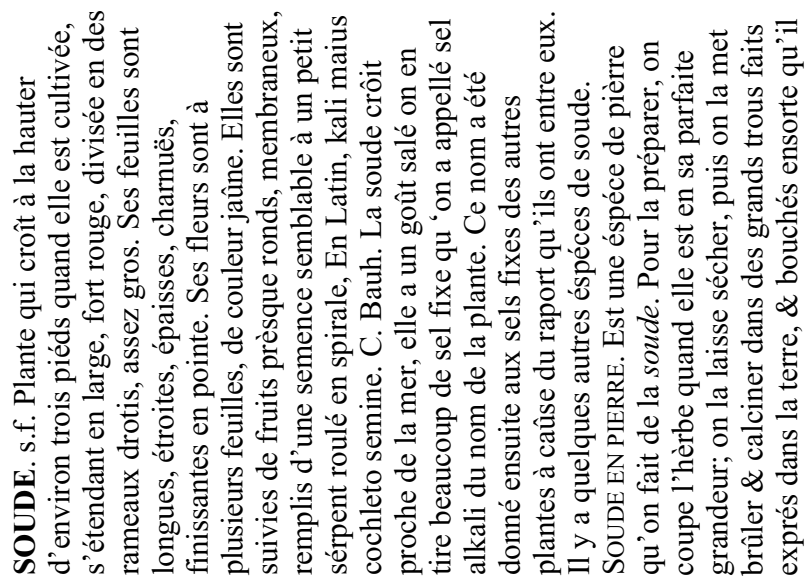 \\
\hline
\end{tabular}




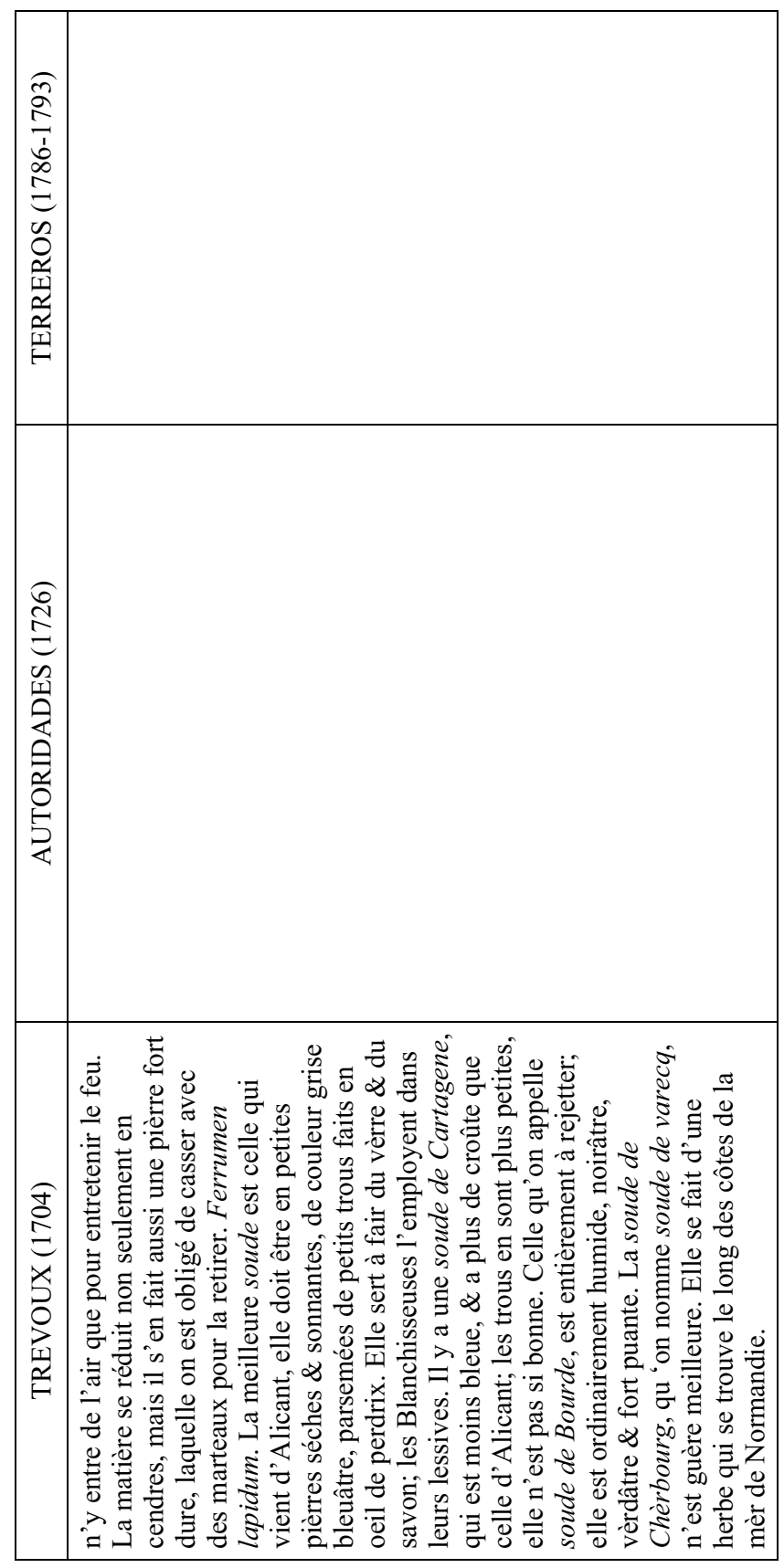

